NASA Technical Memorandum 106941

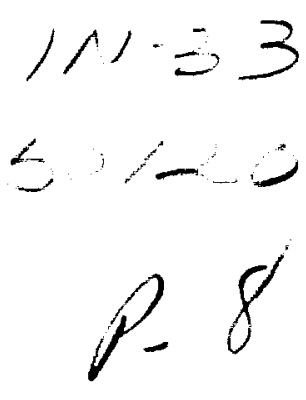

\title{
$77 \mathrm{~K}$ Operation of a Multi-Resonant Power Converter
}

Biswajit Ray

National Aeronautics and Space Administration

Lewis Research Center

Cleveland, Ohio

Scott S. Gerber

NYMA, Inc.

Engineering Services Division

Brook Park, Ohio

Richard L. Patterson and Ira T. Myers

National Aeronautics and Space Administration

Lewis Research Center

Cleveland, Ohio

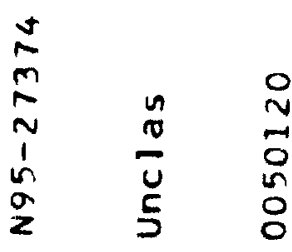

Prepared for the

1995 Power Engineering Society Conference sponsored by the Power Electronics Society of the Institute of Electrical and Electronics Engineers Atlanta, Georgia, June 18-22, 1995

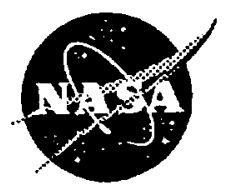

National Aeronautics and Space Administration

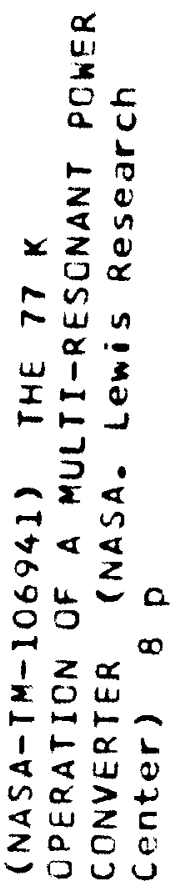




\section{K OPERATION OF A MULTI-RESONANT POWER CONVERTER}

\author{
Biswajit Ray* \\ NRC/NASA Lewis \\ MS: 301-1 \\ 21000 Brookpark Road \\ Cleveland, $\mathrm{OH} 44135$
}

\author{
Scott S. Gerber \\ Nyma, Inc. \\ MS: $301-1$ \\ 2001 Aerospace Parkway \\ Brook Park, OH 44142
}

\author{
Richard L. Patterson \\ NASA Lewis Research Center \\ MS: 301-5 \\ 21000 Brookpark Road \\ Cleveland, OH 44135
}

\begin{abstract}
The liquid-nitrogen temperature $(77 \mathrm{~K})$ operation of a $55 \mathrm{~W}, 200 \mathrm{kHz}, 48 / 28 \mathrm{~V}$ zero-voltage switching multi-resonant dc/dc converter designed with commercially available components is reported. Upon dipping the complete converter (power and control circuits) into liquid-nitrogen, the converter performance improved as compared to the room-temperature operation. The switching frequency, resonant frequency, and the characteristic impedance did not change significantly. Accordingly, the zero-voltage switching was maintained from no-load to full-load for the specified line variations. Cryoelectronics can provide high density power converters, especially for high power applications.
\end{abstract}

\section{Introduction}

A significant amount of work has been done on low-temperature microelectronics including supercomputer, and microwave receivers for radio astronomy and deep-space communication [1]. However, recent advances in high temperature ceramic superconductors, with a transition temperature as high as $\sim 125 \mathrm{~K}$, has generated great interest in low-temperature power electronics that will find applications in diverse fields such as deep-space exploration programs, cryogenic instrumentation, magnetic resonance imaging systems, super-conducting magnetic energy storage systems, high power motors and generators, and switching power conversion systems. The operation of power electronics at low temperatures is expected to result in a more efficient, dense, and reliable system compared to room temperature operation due to better thermal, electrical, and electronic properties of materials at low temperatures. Performance improvement of several bipolar and FET power semiconductor devices at low temperatures has been studied in $[2,3]$.

The objective of this work was to study the feasibility of operating a $\mathrm{dc} / \mathrm{dc}$ power converter in a wide temperature range from $300 \mathrm{~K}$ to $77 \mathrm{~K}$. Potential application of this wide temperature operation includes future deepspace missions. For this purpose, a $48 \mathrm{~V} \pm 20 \% / 28 \mathrm{~V}, 55 \mathrm{~W}$, $200 \mathrm{kHz}$ zero-voltage switching, multi-resonant buck $\mathrm{dc} / \mathrm{dc}$ converter is designed and tested at room temperature $(300 \mathrm{~K})$ as well as liquid nitrogen temperature $(77 \mathrm{~K})$. Experimental results indicate that it is possible to successfully operate resonant converters at $77 \mathrm{~K}$ designed with standard commercially available devices and components. Moreover, efficiency of the power converter did improve slightly at 77 $\mathrm{K}$ as compared to $300 \mathrm{~K}$ operation.

\section{Zero-Voltage Switching Multi-Resonant DC/DC Converter}

The circuit diagram of the constant frequency, zerovoltage switching, multi-resonant (ZVS-MR) buck dc/dc converter is shown in Fig. 1. The multi-resonant switching configuration [4-6] absorbs all major circuit parasitics including junction capacitance of all semiconductor devices and leakage inductance of the transformer winding for transformer isolated topologies. Also, all switching transitions occur at zero-voltage while full dc conversion ratio range is achievable from no-load to full-load keeping the switch current and voltage stresses at a moderate level. The constant frequency ZVS-MR topology is also bidirectional in current and it is inherently protected against short circuit at load terminals under certain conditions $[5,6]$. The converter is regulated against the line and load variations by controlling the duration between turn-off instants of $S_{1}$ and $S_{2}$, where as their turn-on instants are circuit dependent. The ZVS-MR converter has multiple modes of operation [6], and the specific operating mode depends on the converter line and load conditions. Each mode consists of the following four topological stages: $S_{1}$ and $S_{2}$ on, $S_{1}$ on and $S_{2}$ off, $S_{1}$ off and $S_{2}$ on, and $S_{1}$ and $S_{2}$ off. The detailed analysis of the converter operation is discussed in $[5,6]$. The theoretical waveforms for the four modes of operation are shown in Fig. 2, and the dc conversion ratio ( $m \equiv V \mathcal{N}_{\text {in }}$ ) versus normalized load current $\left(I_{O N} \equiv I_{O} Z_{o} / V_{\text {in, }}\right.$ where $Z_{o} \equiv \sqrt{L_{o} / C_{o}}$ ) is shown in Fig. 3 for different values of control duty ratio $\left(D_{c} \equiv \frac{t_{2}-t_{1}}{T_{s}}\right)$. Figures

*National Research Council - NASA Research Associate at Lewis Research Center. 

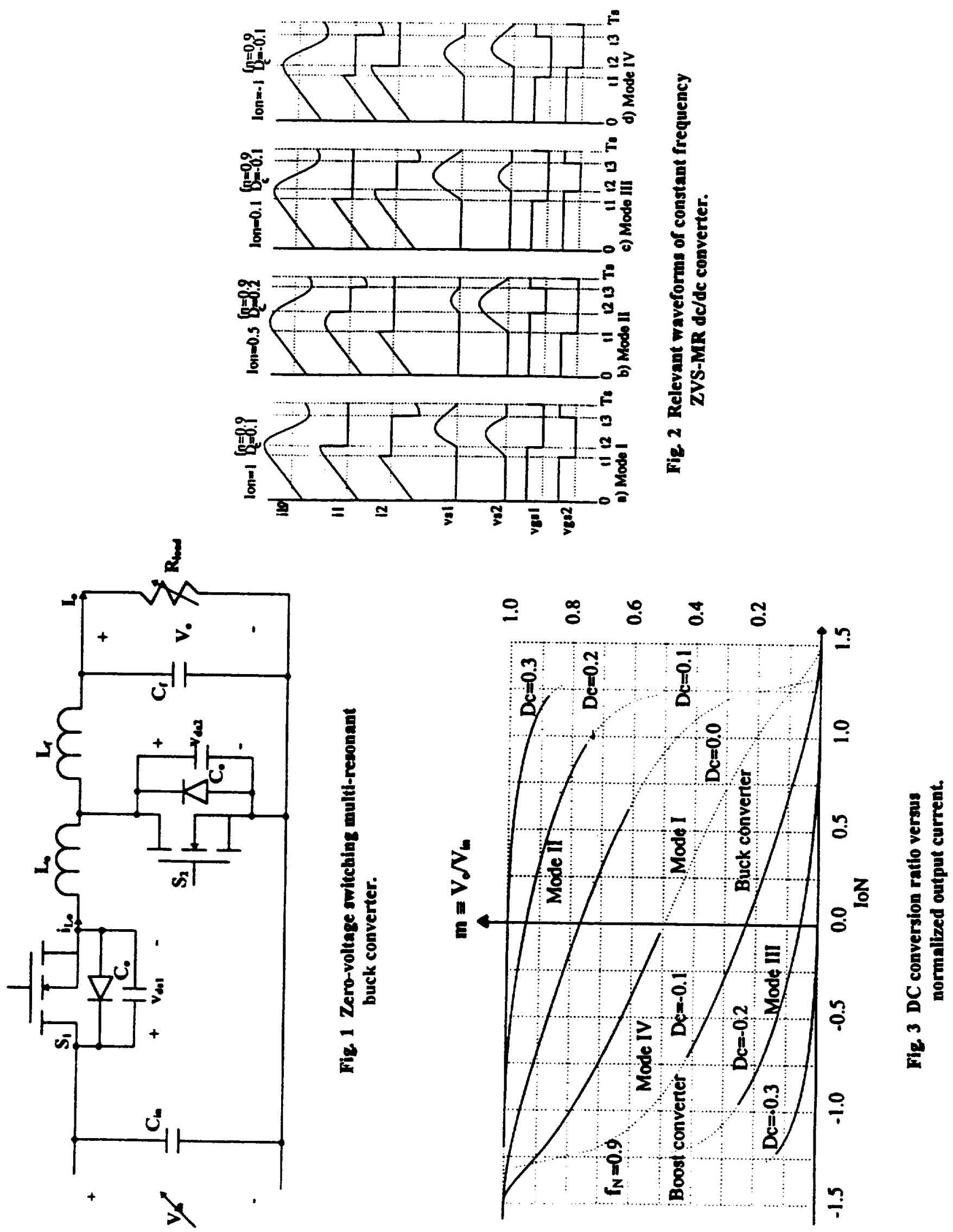
2 and 3 are taken from [6] to be used here in designing the power converter. Both figures are for a normalized switching frequency $\left(f_{N} \equiv\right.$ switching frequency/resonant frequency) of 0.9 . The characteristic impedance of the resonant circuit is given by:

$Z_{0} \leq \frac{I_{O N, \max } V_{m, \min }}{I_{O, \max }}$

Power circuit design: For the $55 \mathrm{~W}, 200 \mathrm{kHz}, 48 \mathrm{~V} \pm 20 \% / 28$ $\mathrm{V}$ converter, $m_{\max }=0.73$ and $m_{\min }=0.49$. From Fig. 3, $\mathrm{I}_{\mathrm{ON}, \max }$ is 1.24 for a normalized switching frequency of 0.9 . The corresponding range of control duty ratio is 0 to 0.25 . Using (1), the characteristic impedance is $24.24 \Omega$. Finally, knowing $f_{\mathrm{N}}$ to be 0.9 , the resonant frequency is $222.2 \mathrm{kHz}$ and the resonant components are $L_{0}=17.4 \mu \mathrm{H}$ and $C_{0}=$ $29.55 \mathrm{nF}$.

\section{Experimental Results and Discussion}

The complete converter circuit is shown in Fig. 4. The resonant and filter inductors used molypermalloy powder (MPP) cores. The input and output filter capacitors are film type and the resonant capacitors are mica and polypropylene types. Two plastic packaged IRF 640 MOSFETs $(18 \mathrm{~A}, 200 \mathrm{~V}, 0.18 \Omega, 430 \mathrm{pF}$ ) are used as power semiconductor switches. The open-loop control circuit uses CMOS timer and driver ICs. The power as well as the control circuits were placed in a $\mathrm{LN}_{2}$ Dewar flask. Also, to observe various current and voltage waveforms using instrumentation at room temperature resulted in a circuit layout with long wires. Data were recorded both at room temperature (RT) and liquid-nitrogen temperature (LNT). The converter was run at full-load for one hour before recording any data either at RT or LNT. For LNT operation, the circuit was first run at RT and then dipped into the Dewar flask while the power was on. In addition the converter was kept in liquid nitrogen for an extended period of time without power and then successfully restarted at 77 $\mathrm{K}$.

Majority carrier devices should exhibit improved speed at temperatures down to $77 \mathrm{~K}$ because of increased carrier mobility due to decreased carrier scattering, increased saturation velocity, reduced junction capacitance and reduced line resistance. For the control circuit design, only the CMOS ICs are used because they are expected to give better overall performance in terms of higher speed and more dense electronic packages and because their performance improves with decreasing temperatures [7]. The signal delay $\left(\tau_{D}\right)$ in going from the input of one device to that of the next is composed of [8] the internal device switching delay $\left(\tau_{\mathrm{sw}}\right)$, the time it takes to charge and discharge $\left(\tau_{L}\right)$ the total load capacitance $\left(C_{L}\right)$ including the wiring capacitance, and the time it takes to charge and discharge $\left(\tau_{j}\right)$ the junction capacitances $\left(C_{D}\right)$. Thus,

$\tau_{D}=\tau_{m}+\tau_{L}+\tau_{J}$

where,

$\tau_{L}+\tau_{J}=\frac{V_{C C}\left(C_{L}+C_{J}\right)}{I_{D, \text { at }}}$

$\tau_{s w}=\frac{L^{2}}{\mu V_{D}}$ for $E \leq E_{\text {sat }}$

or,

$\tau_{\text {so }}=\frac{L}{v_{\text {sed }}}$ for $E \geq E_{\text {sat }}$

In the above equations, $V_{C C}$ and $V_{D}$ are the supply and drain voltages, $I_{D \text {,sat, }}, E_{\text {sat, }}$ and $v_{\text {sat }}$ are the saturation drain current, saturation channel electric field, and saturation channel carrier velocity, and $L$ and $\mu$ are the channel length and channel carrier mobility, respectively.

Timing parameters for the control circuit were recorded when driving a $1000 \mathrm{pF}$ load. The switching frequency changed by only $1 \%$, from $200 \mathrm{kHz}$ at $300 \mathrm{~K}$ to $202 \mathrm{kHz}$ at $77 \mathrm{~K}$. This slight increase in frequency can be attributed to the decreased value of the timing capacitor and faster switching of the semiconductor devices. The rise and fall time of the drive signals decreased only slightly at $77 \mathrm{~K}$. However, the rise and fall delay time of the driver IC improved significantly. Fig. 5 shows the improvement in rise delay time, from $170 \mathrm{nS}$ at $300 \mathrm{~K}$ to $106 \mathrm{nS}$ at $77 \mathrm{~K}$, for the high side driver. The measurements do verify the concept expressed in equations $2-5$.

The measured full-load efficiencies of the converter at RT and LNT are $93.9 \%$ and $94.8 \%$, respectively. The efficiency did improve as expected although by only $0.9 \%$. The circuit loss is $3.64 \mathrm{~W}$ and $3.2 \mathrm{~W}$ at RT and LNT operation, respectively. Relevant converter waveforms for full-load operation are shown in Figs. 6 and 7. As can be seen, the waveforms at RT and LNT are almost identical. The multi-resonant converter topology practically eliminates switching loss; however, the conduction loss is still very much present. The conduction loss of the power MOSFET decreases significantly at LNT due to reduction in drain-tosource resistance caused by increased electron mobility. However, this improvement is greatly offset by increased conduction loss of the MOSFET body-diode. At LNT, the measured forward voltage drop of the body-diode is almost double the RT value.

For zero-voltage turn-on, the body-diode of the power MOSFET is forced to conduct before the device 


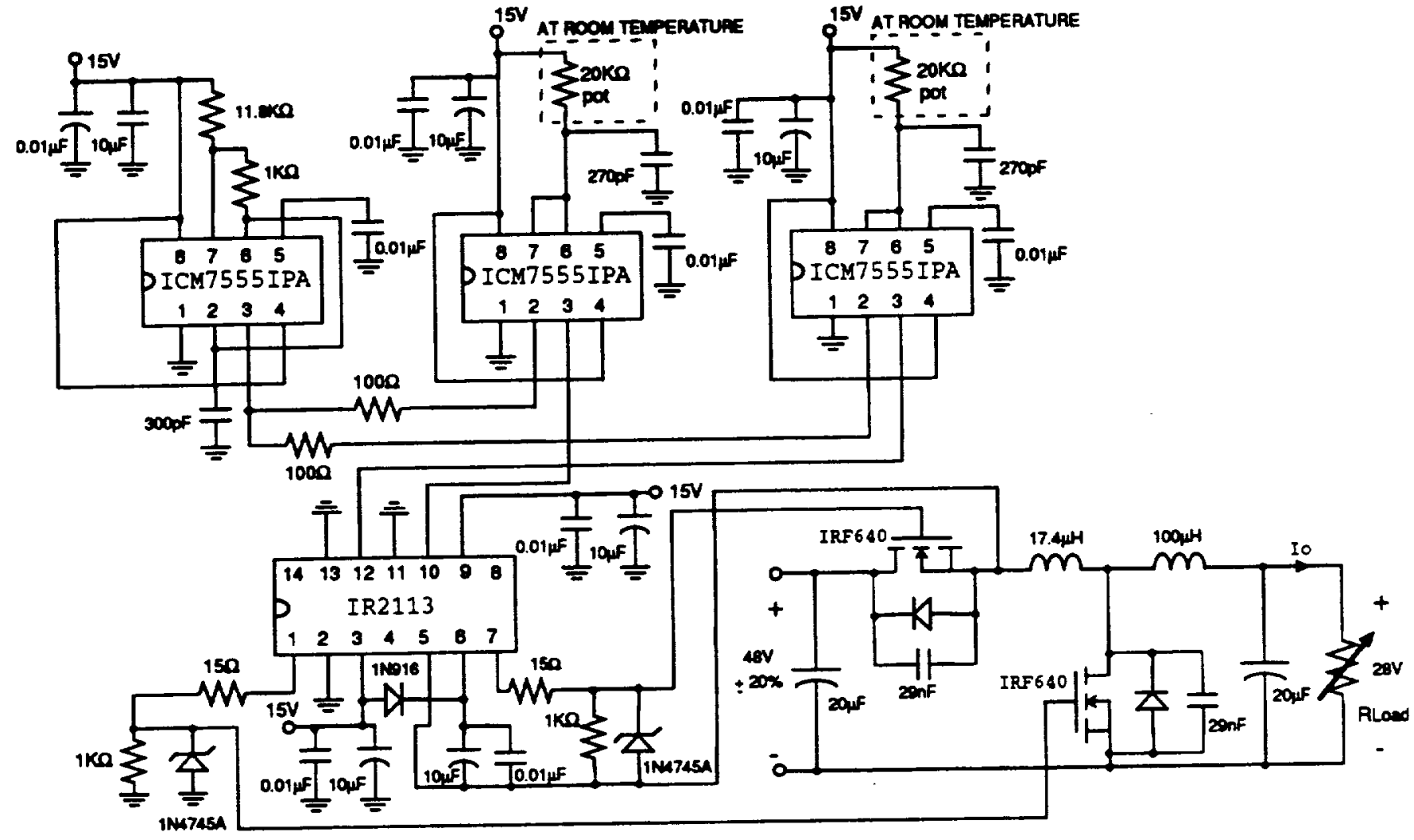

Fig 4 Experimental power converter tested in liquid nitrogen.

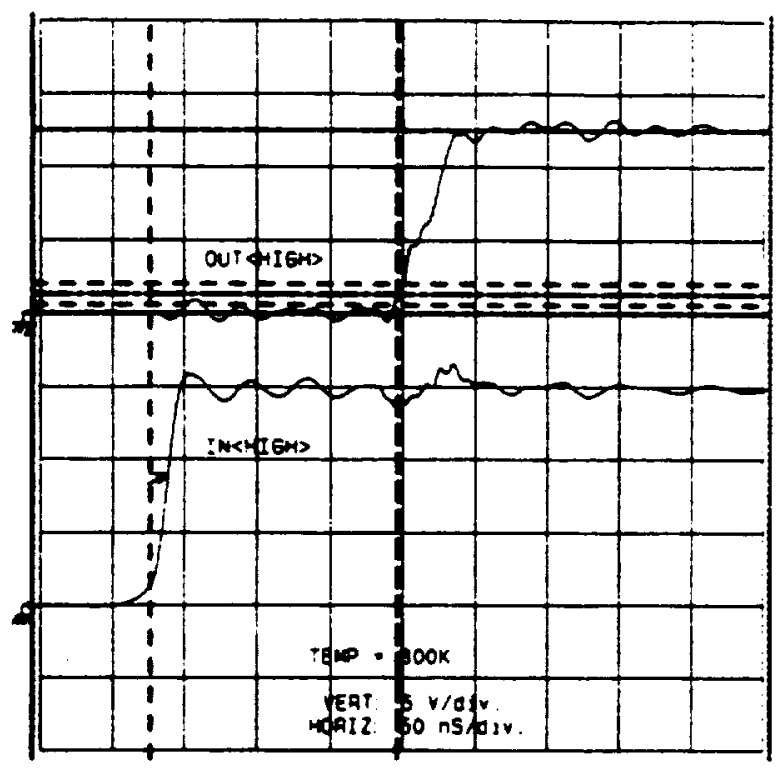

(a) $300 \mathrm{~K}$ operation

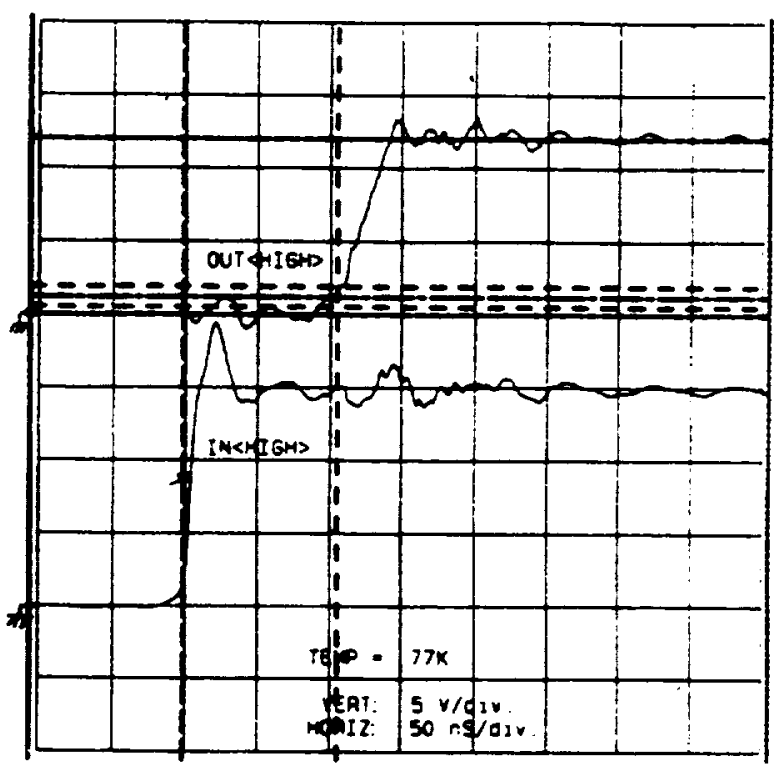

(b) $77 \mathrm{~K}$ operation

Fie 5 Rixe delay time of the high-side driver. 


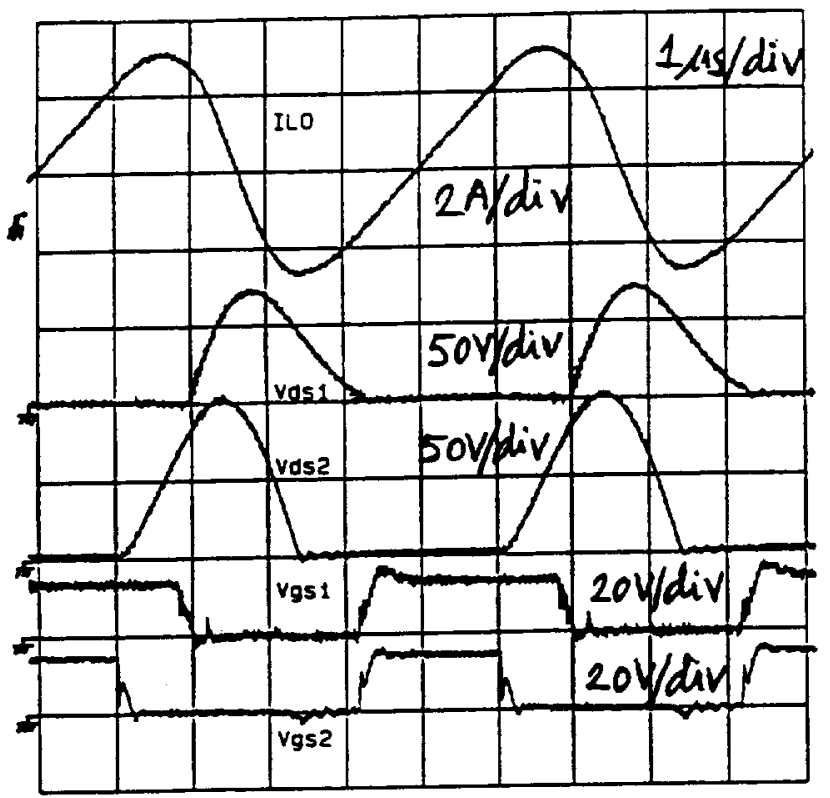

Fig 6 Converter waveforms at room temperature under full-load condition. $\left.V_{b}=48.3 \mathrm{~V}, \mathrm{I}_{\mathbf{l}}=1.24 \mathrm{~A}, \mathrm{~V}_{\bullet}=28.6 \mathrm{~V}, \mathrm{I}_{0}=1.965 \mathrm{~A}\right)$

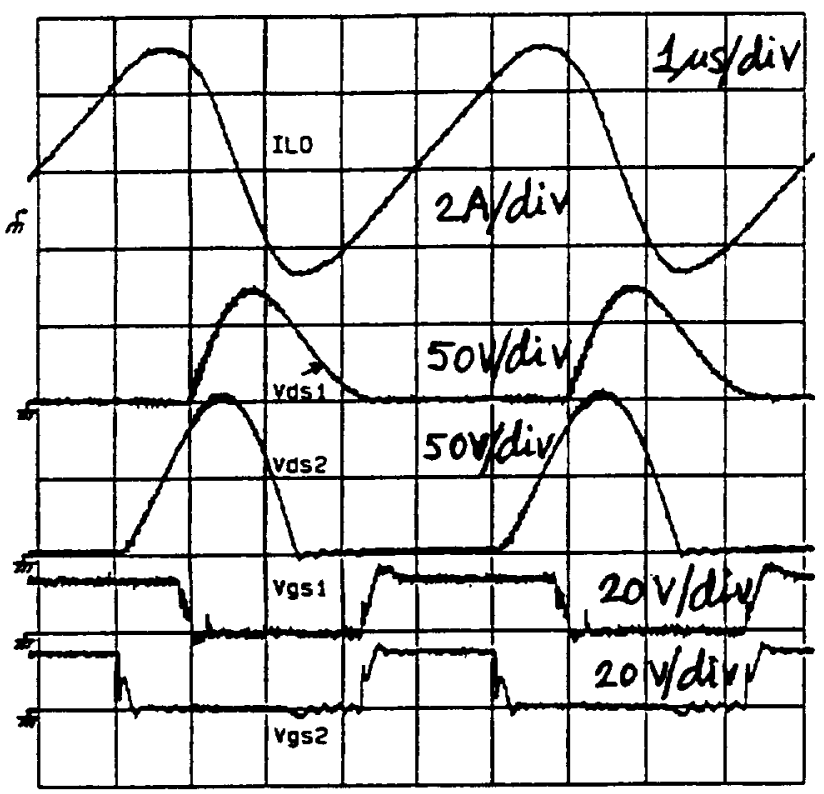

Fig 7 Converter waveforms at liquid nitrogen temperature under full-load condition.

$\left(V_{m}=48.3 \mathrm{~V}, I_{l}=1.265 \mathrm{~A}, V_{\bullet}=28.98 \mathrm{~V}, \mathrm{I}_{\bullet}=1.99 \mathrm{~A}\right)$

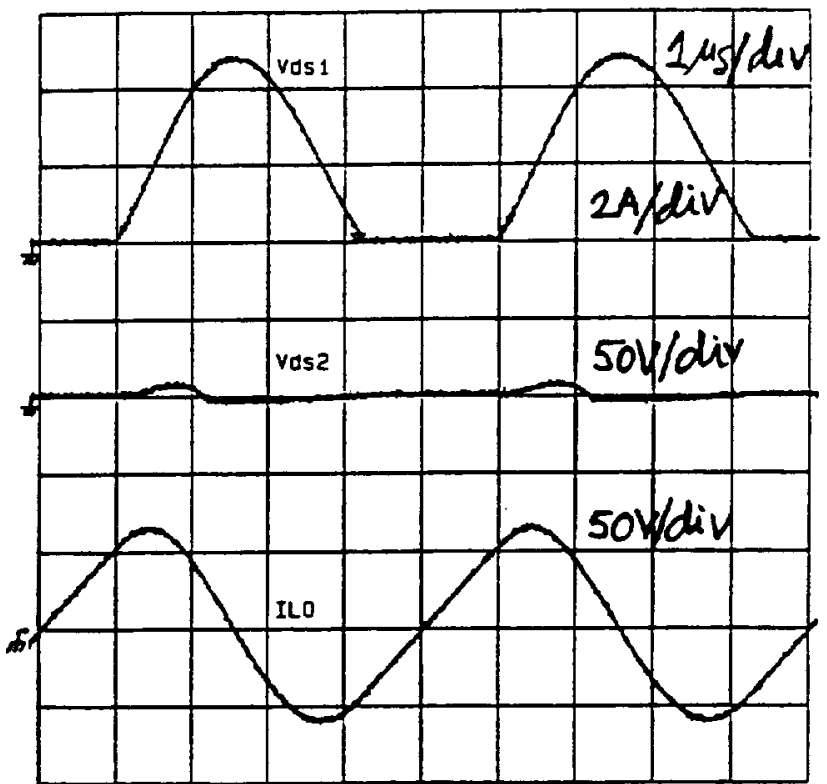

Fig 8 Converter waveforms at room temperature under short circuit condition.

$\left(V_{m}=48 \mathrm{~V}, I_{i=}=0.095 \mathrm{~A}, I_{+}=2.21 \mathrm{~A}\right)$

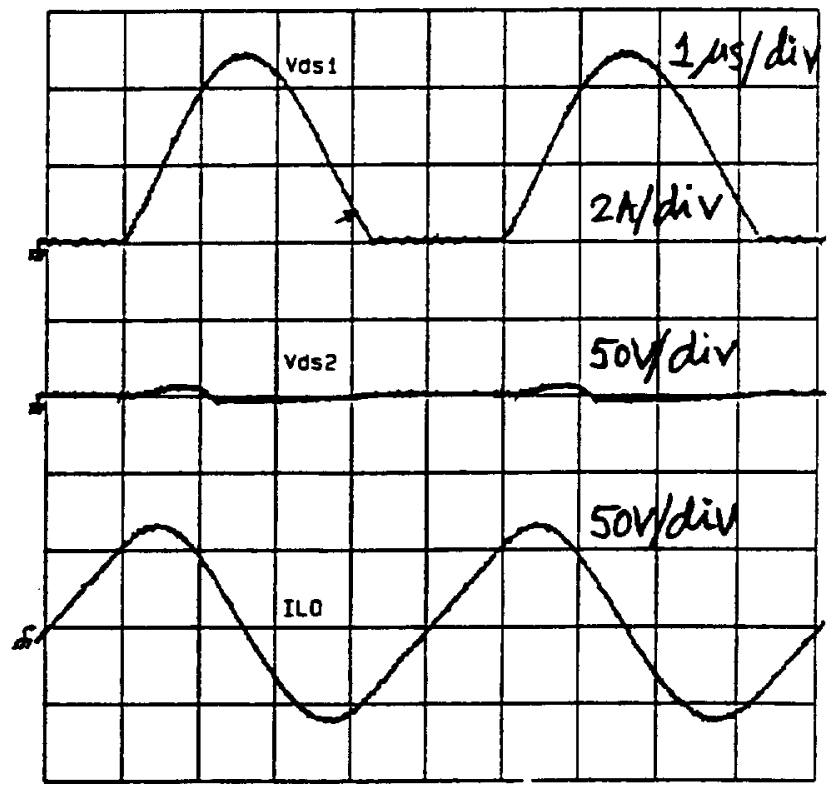

Fie 9 Converter waveforms at liquid nitrogen temperature under short circuit condition. $\left.V_{b}=48 \mathrm{~V}, I_{w}=0.091 \mathrm{~A}, I_{0}=2.27 \mathrm{~A}\right)$ 
conducts in the forward direction. Accordingly, the total conduction loss in the switch is composed of the MOSFET conduction loss and the body-diode conduction loss. As discussed in the previous paragraph, the MOSFET conduction loss decreases with decreasing temperatures where as the body-diode conduction loss increases. The improvement in switch conduction loss can be significant if the MOSFET is used only in the forward conduction mode without using its body-diode. This leads to the fact that the zero-voltage switching may not be the optimal resonant topology if the improvement in switch conduction loss at low temperatures is critical. However, the half-wave zerocurrent switching resonant topology [9] could be used to exploit the low temperature characteristic of MOSFETs without using the body-diode. The zero-voltage switching is preferred over zero-current switching at RT because of lower conduction loss and lower peak current stress. If zerocurrent switching resonant topology is used for low temperature operation, neither the conduction loss nor the peak current stress is a problem. At low temperatures, conduction loss reduces significantly due to increased carrier mobility, and also a given device can carry much higher current compared to RT due to increased mobility and increased substrate and metal thermal conductivities.

In terms of passive components, the measured MPP inductor loss at LNT remained practically the same as that at RT. The eddy-current loss is expected to increase at low temperatures due to decreased core resistivity [10] and the winding loss is expected to decrease due to decreased resistance. The film and mica capacitors are usable at low temperatures as they show a very small drop in capacitance and are relatively stable [11]. The overall low-temperature effect of inductors and capacitors on the converter performance was found to be relatively small. The resonant frequency and the characteristic impedance of the converter remained practically unchanged at LNT, and accordingly did not alter the available load range and zero-voltage switching was maintained for both switches from no-load to full-load. This was possible to achieve because the switching frequency of the converter increased by only $1 \%$, from $200 \mathrm{kHz}$ at 300 $\mathrm{K}$ to $202 \mathrm{kHz}$ at $77 \mathrm{~K}$. This change in switching frequency is highly dependent on the manufacturer and type of CMOS ICs used in designing the control circuit. In general, the switching frequency may vary unpredictably and therefore, constant frequency resonant topologies may not be able to achieve resonant switching under full load and line variations. However, the variable frequency resonant topologies might be able to achieve resonant switching even at low temperatures.

The ZVS-MR converter is capable of sustaining a short circuit at the load terminals for a limited range of control duty ratio as can be seen in Fig. 3 . This characteristic is experimentally verified both at RT and LNT, and the corresponding experimental waveforms are shown in Figs. 8 and 9, respectively. For higher values of control duty ratio, the converter can sustain a short circuit condition. However, $S_{1}$ no longer switches at zero-voltage and accordingly the switching loss increases significantly.

\section{Conclusions}

It is possible to design and operate power electronic converters at low temperatures using commercially available components. Overall, the converter performed satisfactorily both at RT and LNT. Slight improvement in performance was observed at LNT with no visible degradation. The converter restarted successfully at $77 \mathrm{~K}$. The thermal cycling and reliability issues were not addressed in this work. However, for future space or industrial application of low temperature electronics, the thermally activated electronic, electrical, and mechanical issues must be investigated.

\section{References}

1. R. K. Kirschman, "Low-temperature semiconductor electronics," Proc. Symp. Low Temperature Electronic Device Operation, Vol. 91-14, pp. 1-12, The Electrochemical Society, 1991.

2. J. L. Hudgins, S. Menhart, and W. M. Portnoy, "The low temperature switching performance of thyristors and MOSFETs," IEEE-PESC Rec., pp. 429-434, June 1990.

3. O. M. Mueller and K. G. Herd, "Ultra-high efficiency power conversion using cryogenic MOSFETs and HT-superconductors," IEEE-PESC Rec., pp. 772-778, June 1993.

4. W. A. Tabisz, M. M. Jovanovic, and F. C. Lee, "High-frequency multi-resonant converter technology and its applications," IEE Conf., July 1990.

5. D. Maksimovic and S. Cuk, "Constant frequency control of quasi-resonant converters," IEEE Trans. Power Electronics, Vol. 6, No. 1, pp. 141-150, Jan. 1991.

6. Z. R. Martinez and B. Ray, "Bidirectional dc/dc power conversion using constant frequency multi-resonant topology," IEEE-APEC Rec., pp. 991-997, Feb. 1994.

7. M. J. Deen, "Low temperature microelectronics: opportumities and challenges," Proc. Symp. Low Temperature Electronic Device Operation, Vol. 91-14, pp. 25-38, The Electrochemical Society, 1991.

8. S. M. Sze, "Physics of semiconductor devices," page-454, 2nd. ed., Wiley-Interscience, 1981.

9. F. C. Lee, "High-frequency quasi-resonant and multi-resonant converter technologies," Proc. IEEE Int. Conf. Ind. Electronics, pp. 509-521, Oct. 1988.

10. F. W. Ackermann and W. A. Klawitter, "Magnetic properties of commencial soft magnetic alloys at cryogenic temperatures," Adv. Cryogenic Engr., Vol. 16, pp. 46-50, Plenum Press, 1971.

11. R. Blanchard and R. Severns, "Designing switch-mode power converters for very low temperature operation," Proc. Powercon 10, pp. D-2.1-D-2.11, 1983. 
Public reporting burden for this collection of intormation is estimated to average 1 hour per response, including the time for reviewing instructions, searching existing data soufces, gathering and maintaining the data needed. and completing and reviewing the collection of inlormation. Send commonts reganding inis bu den estimale or any olher aspect of this Davis Highway. Suite 1204. Arlington. VA 22202-4302, and to the Ottice of Management and 8udget, Paperwork Reduction Projed (0704-0188). Washington. DC 20503.

\begin{tabular}{|l|l|l}
\hline 1. AGENCY USE ONLY (Leave blank) & $\begin{array}{c}\text { 2. REPORT DATE } \\
\text { May } 1995\end{array}$ & $\begin{array}{r}\text { 3. REPORT TYPE AND DATES COVERED } \\
\text { Technical Memorandum }\end{array}$
\end{tabular}

4. TITLE AND SUBTITLE

5. FUNDING NUMBERS

77 K Operation of a Multi-Resonant Power Converter

6. AUTHOR(S)

WU-233-02-0C

Biswajit Ray, Scott S. Gerber, Richard L. Patterson, and Ira T. Myers

7. PERFORMING ORGANIZATION NAME(S) AND ADDRESS(ES)

8. PERFORMING ORGANIZATION REPORT NUMBER

National Aeronautics and Space Administration

Lewis Research Center

Cleveland, Ohio 44135-3191

E-9669

9. SPONSORING/MONITORING AGENCY NAME(S) AND ADDRESS(ES)

10. SPONSORING/MONITORING AGENCY REPORT NUMBER

National Aeronautics and Space Administration

Washington, D.C. 20546-0001

NASA TM-106941

\section{SUPPLEMENTARY NOTES}

Prepared for the 1995 Power Engineering Society Conference sponsored by the Power Electronics Society of the Institute of Electrical and Electronics Engineers, Atlanta, Georgia, June 18-22, 1995. Biswajit Ray, National Research CouncilNASA Research Associate at NASA Lewis Research Center, on leave from the University of Puerto Rico, Mayaguez Campus; Scott S. Gerber, NYMA, Inc., Engineering Services Division, 2001 Aerospace Parkway, Brook Park, Ohio 44142 (work funded by NASA Contract NAS3-27186); Richard L. Patterson and Ira T. Myers, NASA Lewis Research Center. Responsible person, Richard L. Patterson, organization code 5430, (216) 433-8166.

12a. DISTRIBUTIONAVAILABILTY STATEMENT 12b. DISTRIBUTION CODE

Unclassified - Unlimited

Subject Categories 33 and 20

This publication is available from the NASA Center for Aerospace Information. (301) 621-0390.

13. ABSTRACT (Maximum 200 words)

The liquid-nitrogen temperature ( $77 \mathrm{~K}$ ) operation of a $55 \mathrm{~W}, 200 \mathrm{kHz}, 48 / 28 \mathrm{~V}$ zero-voltage switching multi-resonant dc/ $\mathrm{dc}$ converter designed with commercially available components is reported. Upon dipping the complete conventer (power and control circuits) into liquid-nitrogen, the converter performance improved as compared to the room-temperature operation. The switching frequency, resonant frequency, and the characteristic impedance did not change significantly. Accordingly, the zero-voltage switching was maintained from no-load to full-load for the specified line variations. Cryoelectronics can provide high density power converters, especially for high power applications.

\section{SUBJECT TERMS}

Cold electronics; Low temperature; Electronics; Power

17. SECURTY CLASSIFICATION OF REPORT Unclassified
18. SECURITY CLASSIFICATION OF THIS PAGE Unclassified
19. SECURITY CLASSIFICATION OF ABSTRACT Unclassified 


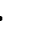

